\title{
Foley's catheter dilatation in the management of choanal atresia: A prospective non-randomized case-series
}

\author{
Original \\ Article \\ Ahmed Mohammed Abdelghany \\ Department of Otorhinolaryngology, Faculty of Medicine, Benha University, Egypt.
}

\begin{abstract}
Background: Choanal atresia treatment is by operative opening of the choana using a transnasal or transpalatal approaches. The main goals of the surgery are creating a satisfactory opening and guarding against restenosis. Many surgeons use stents aiming to prevent or minimize restenosis. Searching for a feasible method decreasing the incidence of restenosis and abolishing the need for stents; we thought of Foley's catheters' dilatation during and after the surgical correction of the atresia.

Patients and Methods: A non - randomized prospective single-blinded case series study. After finishing the bony and soft tissue work, we applied Foley's catheter (size 12 Fr) in the new opening, inflated with normal saline to its maximum capacity for 3 minutes, deflated for one minute then re-inflated for another 3 minutes. No packs or stents were placed. In the follow up visits and under endoscopic vision, the surgical opening was routinely dilated with 12 or 14 FR Foley's catheters.

Results: Fourteen infants were included with age ranging from 3 to 11 days (mean 6.14). Twelve cases (85.7\%) showed criteria of success at the end of the follow up period. Two cases (14.3\%) needed revision surgery at ages of 4 and 6 months. They had considerable granulations that were refractory to balloon dilatation and conservative treatment and led to considerable stenosis.

Conclusion: Using Foley's catheters is a feasible, effective, safe and cheap alternative for dilatation of the new choanae in choanal atresia repair. It eliminates the need for stenting and may be a satisfactory alternative for other maneuvers.
\end{abstract}

Key Words: Atresia, choanal, dilatation, foley, stents.

Received: 14 February 2020, Accepted: 24 April 2020

Corresponding Author: Ahmed Mohammed Abdelghany, MD, Benha Faculty of Medicine, Tel.: 01226200444, E-mail: ahmedent@gmail.com

ISSN: 2090-0740, November 2020 Vol.21, No.3

\section{INTRODUCTION}

Choanal atresia is a developmental failure of the posterior nasal cavity to communicate with the nasopharyn $x^{[1]}$. It is a relatively rare phenomenon, with a global incidence of between 1 in 3000 to 1 in 8000 live births ${ }^{[2]}$, with unknown incidence in our country that may be higher. It is more often unilateral than bilateral $(60 \%: 40 \%)$. Approximately two thirds of patients suffer from further malformations ${ }^{[3]}$.

Usually, treatment is by operative opening of the choana using a transnasal or transpalatal approach, the former is generally preferred for infants and the latter may be more preferable in older children and adults.

Once the atresia is surgically corrected, the surgeon usually follows up for possible impending restenosis. Pirsig $^{[4]}$ noted that restenosis often becomes a problem because of the small dimensions of the opened area, and usually starts from the cranial and lateral borders of the new choana, or develops from excessive granulations.
Other risk factors for restenosis include nasopharyngeal reflux, gastroesophageal reflux, age $<10$ days (associated with limited visualization in noses of neonates and limited resection of the vomer), bilateral atresia with purely bony atretic plate and the presence of associated malformations ${ }^{[5]}$. Frequent post-operative use of nasal saline irrigation and periodic endoscopic surveillance or second look procedures can improve the primary repair success and reduce the rate of restenosis ${ }^{[6]}$.

Many surgeons use stents aiming to prevent or minimize restenosis. However; recent reports claim that stenting may be a stimulant for more stenosis ${ }^{[7]}$. We noticed other problems of stenting, such as the need of frequent cleaning due to tubes' obstruction, internal nasal and septal abrasions, columellar tears, anterior nasal apertures chondritis and disfigurement and psychic depression of the mother. Other methods aiming at reducing restenosis rate include creation of septal flaps and Mitomycin-C application. 
Foley's catheters are cheap and available inflatable balloon catheters that have many sizes (from 12 to 40 Fr units). It has a balloon (or two) that can be inflated to variable sizes with air or fluid. The pressure in the balloon is generally low and never reaches a harmful level to the surrounding tissues. Foley's catheter was originally invented for evacuation of urine, now it is widely used in multiple applications in ENT surgery. It is used effectively in the management of posterior epistaxis ${ }^{[8]}$, to control postoperative bleeding from the maxillary sinus ${ }^{[9]}$, in frontal sinus surgery ${ }^{[10]}$, in reduction of facial fractures ${ }^{[1]]}$.

Searching for a feasible method decreasing the incidence of restenosis and abolishing the need for stents; we thought of Foley's catheters dilatation during and after the surgical correction of the atresia.

\section{PATIENTS AND METHODS:}

A case-series prospective non-randomized study; conducted on fourteen cases of bilateral choanal atresia in non-syndromatic infants during the period from January 2014 to October 2018. Each case had a signed informed consent from the parent.

Infants presented with neonatal cyanosis and failure to pass suction catheter through the nose immediately after birth. They were intubated and admitted to pediatric ICUs.

All infants had preoperative brain and PNS CTs, echocardiography and full pediatric consultation. All were suffering from bilateral complete choanal atresia.

\section{Surgery}

Surgeries were done in a specialized children hospital and in a specialized ENT center by the author.

The surgeries were done under general anesthesia with oral endotracheal intubation. Using $11 \mathrm{~cm} 2.7 \mathrm{~mm}$ monitored endoscope; 0 and 30 degrees and led light sources; the atretic plates were diathermied, opened then widened to their maximum dimensions using the conventional instruments and microdebriders. The posterior part of the bony septum was excised in all cases connecting the 2 choanae into one wide opening. Securing hemostasis with compression, adrenaline wicks and sometimes with radiofrequency coagulation.
After finishing the bony and soft tissue work, we started applying Foley's catheter (size 12 Fr) balloon in the new opening, inflated it with normal saline to its maximum capacity $(5-10 \mathrm{cc})$ for 3 minutes, deflated for one minute then re-inflated for another 3 minutes. (Figure 1). Catheter size refers to the circumference of the catheter, not the luminal diameter and is recorded in French sizes $(1 \mathrm{Fr}=0.33 \mathrm{~mm})$. No packs or stents were placed.

\section{Postoperative care}

The infant was returned to his ICU; without endotracheal tubes (unless needed for other conditions); for at least 48 hours, during which, the infant was in alternating lateral positions, monitored for vital signs, evidence of bleeding and received decongestant nasal drops every 30 minutes for 3 hours. The infant was examined endoscopically every 12 hours for bleeding or large clots.

After discharge, the parents were instructed to wash the infant's nose with "sea-water" spray three times /day for a month and giving a prophylactic antibiotic for one week.

\section{Follow up and the dilatation regimen}

Visits were fashioned every week for one month, every 2 weeks for the next 2 months then monthly for the next 9 months unless symptoms of obstruction appear Overall follow up period was one year after the last surgery.

In the follow up visits and under endoscopic vision, and after application of local anesthesia spray, the surgical opening was routinely dilated during visits in the $1^{\text {st }} 3$ months with 12 or 14 FR Foley's catheters. After the $3^{\text {rd }}$ month, dilation was done on need only. We applied inflation for only 20-30 seconds 2 times with 3 minutes interval. (Figure 2).

If granulations started to appear (Figure 3), we gave the infant a 14 days course of local nasal drops containing dexamethasone and garamycin and the dilatation becomes weekly till their regression.

The primary outcome measures were the adequacy of the new choanal opening as judged endoscopically (objective) and absence of symptoms of nasal obstruction (subjective) at one year after the first surgery. 

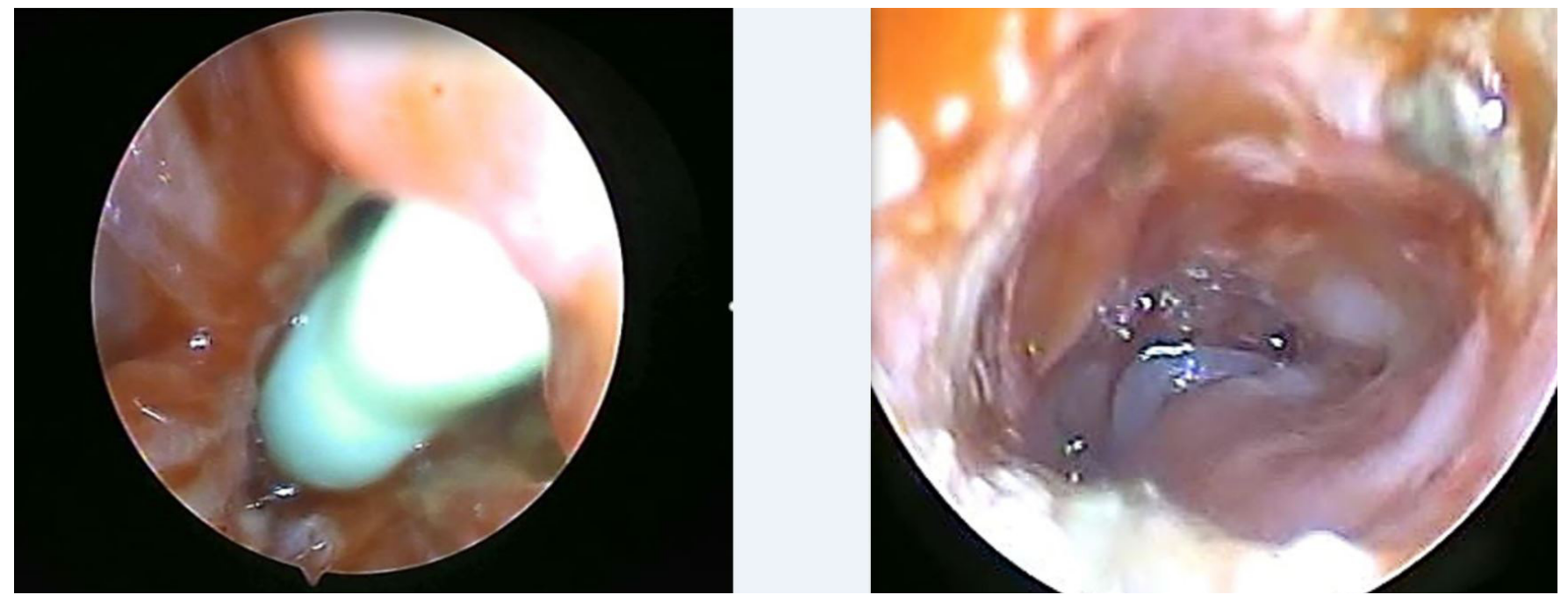

Fig. 1: A: inflated Foley's catheter in the new choana. B: After dilation

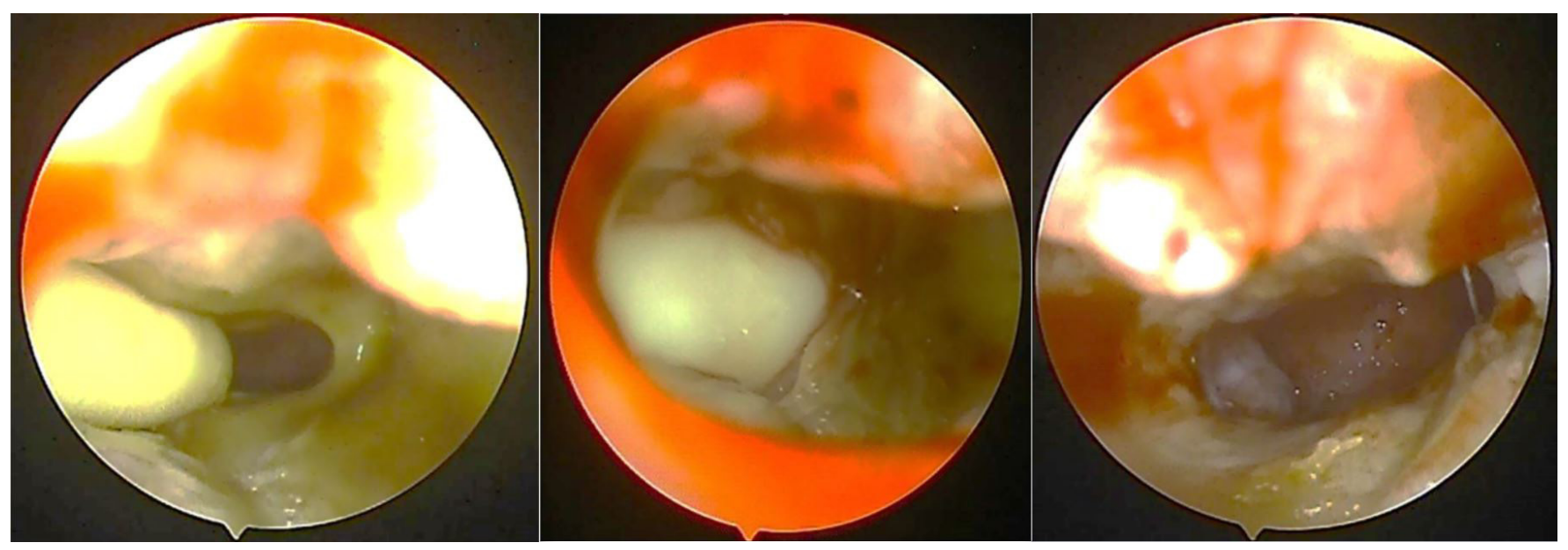

Fig. 2: postoperative dilatation: A: the stenosed Choana B: the inflated Foley's catheter in the stenosed choana C: after dilatation

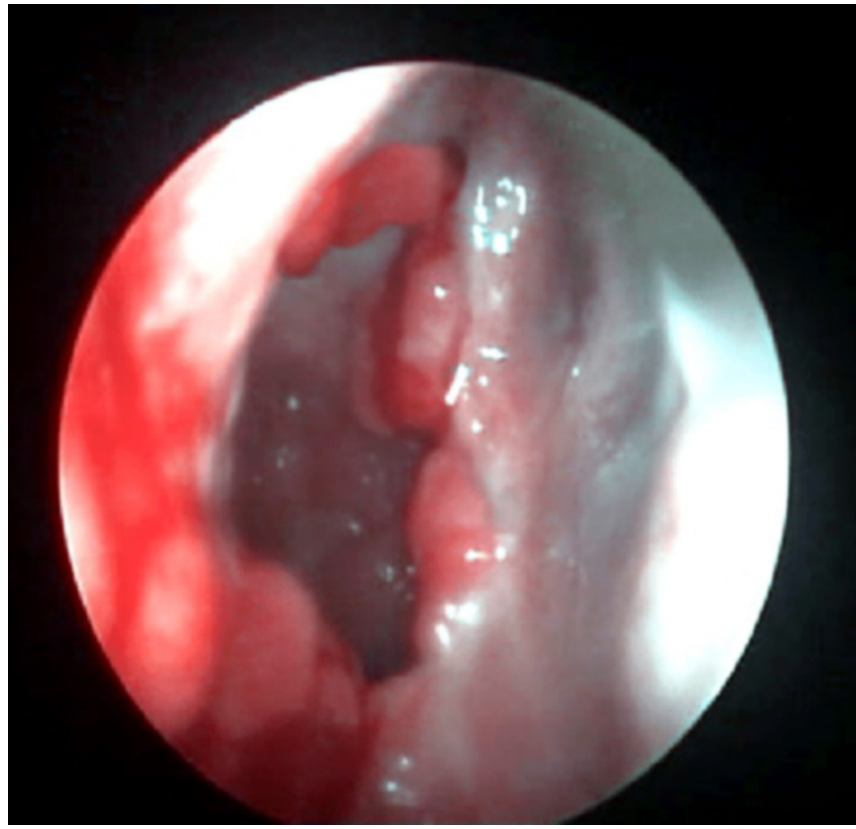

Fig. 3: Granulations in the right new choana 


\section{RESULTS:}

The series included 14 infants; 8 males and 6 females with age ranging from 3 to 11 days at time of surgery (mean 6.14 days). Nine had bony atresia while five had mixed type. (Table 1) shows data sheet of enrolled patients (Table 1).

Twelve of fourteen cases $(85.7 \%)$ showed criteria of success at the end of the follow up period. Eight of fourteen cases needed dilatation after the 1 st 3 months. The mean number of extra-dilatations was 3.5 dilatations / patient.

Granulations occurred in 6 infants $(43 \%) ; 4$ of them were managed successfully by balloon dilatation and conservative treatment mentioned before and 2 were refractory and progressed to complete stenosis and needed revision surgery at ages of 4 and 6 months. Those two cases were having bony type of atresia. Revised cases were managed by the same primary way, but no or minimal bony work was needed. Most of soft tissue was removed by microdebrider followed by dilatation with Foley's catheter. One year after the revision, no cases with stenosis were noted.

Apart from granulations and stenosis, no other complications were noted during the follow up period.

Table 1: data sheet of the patients:

\begin{tabular}{|c|c|c|c|c|c|c|c|}
\hline : & Gender & $\begin{array}{c}\text { Type of } \\
\text { obstruction }\end{array}$ & $\begin{array}{c}\text { Age at surgery } \\
\text { (days) }\end{array}$ & $\begin{array}{c}\text { Postoperative } \\
\text { granulations }\end{array}$ & $\begin{array}{l}\text { Need for } \\
\text { revision }\end{array}$ & $\begin{array}{l}\text { Number of } \\
\text { dilatations } \\
\text { after } 3 \text { months } \\
\text { postop }\end{array}$ & $\begin{array}{c}\text { Age at revision } \\
\text { surgery } \\
\text { (months) }\end{array}$ \\
\hline 1 & Female & Bony & 3 & + & + & 4 & 4 \\
\hline 2 & Male & Mixed & 5 & - & - & 2 & - \\
\hline 3 & Male & Bony & 10 & - & - & - & - \\
\hline 4 & Female & Bony & 4 & + & + & 6 & 6 \\
\hline 5 & Female & Mixed & 5 & + & - & - & - \\
\hline 6 & Male & Bony & 5 & - & - & 2 & - \\
\hline 7 & Male & Mixed & 11 & - & - & - & - \\
\hline 8 & Female & Bony & 7 & - & - & 3 & - \\
\hline 9 & Male & Bony & 5 & + & - & 3 & - \\
\hline 10 & Male & Bony & 7 & - & - & 3 & - \\
\hline 11 & Male & Mixed & 6 & + & - & 5 & - \\
\hline 12 & Female & Mixed & 11 & - & - & - & - \\
\hline 13 & Male & Bony & 3 & + & - & - & - \\
\hline 14 & Female & Bony & 4 & + & - & - & - \\
\hline
\end{tabular}




\section{DISCUSSION}

In this study, we tried to assess the effectiveness of intra- and post-operative Foley's catheter dilatation in repair of choanal atresia.

Foley's catheters can be inflated to variable sizes with air or fluid. The pressure in the balloon is generally low. To the best of our knowledge, dilatation balloons are not easily available in a size suitable for a relatively wide new choana. In addition, large- size balloons are expensive and their pressure is higher than that of Foley' catheters inflated balloons. So, Foley's catheters can be a feasible, cheap and safer alternative for dilatation.

We did not need to place stents in the new choana, did not use Mitomycin C or use the time-consuming and relatively difficult septal flaps.

Metallic dilators are sometimes used for postoperative dilatation. They carry some disadvantages, the most apparent of which is the larger new choanal size than the anterior nostril; limiting the procedure of dilatation to nostril size. Also balloon dilatation is circumferential and more effective than the pushing dilatation of metallic dilators

In our study; using Foley's catheters in choanal atresia surgery was associated with a satisfactory primary success rate; $85.7 \%$. Other studies have reported primary repair success rates ranging from 67 to $88 \%{ }^{[12]}$. Transnasal endoscopic repair scored mean success rate $85.3 \%$ in a meta-analysis of 20 studies $^{[13]}$. This match with our results although our small number of cases cannot yield strong statistical data to compare satisfactory with larger studies. R Riepl et $a{ }^{[14]}$ reported $100 \%$ success in 6 cases managed with intraoperative balloon dilatation during surgical correction followed by stenting. Joshua Bedwell et al ${ }^{[15]}$ used high-pressure balloons in dilating the posterior choana in 5 patients with success without complications.

It is somewhat difficult to compare different primary success rates because of the wide differences in definitions of failed cases necessitating revision. Some surgeons consider revision (failure) as any maneuver requiring general anesthesia ${ }^{[16]}$; others consider it as removal of granulations. We considered failure as considerable closure of the new choanae (with granulations or stenosis) sufficient to produce permanent complaint of nasal obstruction.

The duration of intraoperative balloon dilatation was 3 minutes which was longer than that in the follow up visits ( 30 seconds) as the infant during the operation was breathing through the endotracheal tube, while was breathing from his nose in the follow up visits.

The frequency of visits should increase in cases of impending stenosis as the low-pressure Foley's catheter can dilate early stenoses but it would be weaker than required for fibrotic older stenoses.

Infection and granulations are thought to be the cause of restenosis after this technique. Revision cases were the youngest in age and the least in weight. This may be a predictor factor for failure that may guide to waiting for more days to gain more weight. This is in agreement with Natacha et $a l^{[17]}$ and Friedman et $a l^{[18]}$.

\section{CONCLUSION}

In choanal atresia repair; intraoperative and postoperative dilatation of the new choana with Foley's catheter is an effective, feasible, simple, safe and cheap method that yielded satisfactory success. It eliminates the need for stenting and can be a satisfactory alternative for other expensive and complex maneuvers.

\section{CONFLICT OF INTEREST}

There are no conflicts of interest.

\section{REFERENCES}

1. Rizzo KA, Kelly MF, Lowry LD. Diagnosis and treatment of congenital choanal atresia: Trans Pa Acad Ophthalmol Otolaryngol. 1989; 41:842-6.

2. Natacha Teissier, Florentia Kaguelidou, Vincent Couloigner, Martine Francois, Thierry Van Den Abbeele. Predictive Factors for Success After Transnasal Endoscopic Treatment of Choanal Atresia: Arch Otolaryngol Head Neck Surg. 2008 Jan 134 (1), 57-61.

3. Stankiewicz JA. The endoscopic repair of choanal atresia. Otolaryngol Head Neck Surg. 1990;103(6):931-937.

4. Pirsig W. Surgery of choanal atresia in infants and children: historical notes and updated review. Int $\mathrm{J}$ Pediatr Otolaryngol. 1986;11;153-170.

5. Newman JR, Harmon P, Shirley WP, Hill JS, Woolley AL, Wiatrak BJ. Operative management of choanal atresia: a 15-year experience. JAMA Otolaryngol Head Neck Surg (2013) 139(1):71-5.

6. Rodriguez H, Cuestas G, Passali D. A 20-year experience in microsurgical treatment of choanal atresia. Acta Otorrinolaringol Esp (2014) 65(2):85-92. 
7. Abdelaziz Elsherif, Yosry Osman, Abobakr Abdelmoghny, Ahmed Mahrous. Endonasal repair of choanal atresia, does stenting have a better outcome?: Egyptian Journal of Ear, Nose, Throat and Allied Sciences. 2012; 13: 13-17.

8. Dennis Pashen. Management of epistaxis in general practice. Article in Australian family physician. 2002 August. 31(8)

9. Hiroyuki Zusho, Michinari Okamoto, JIBI Inkoko Tembo. Utilization of Foley Balloon Catheter in Otolaryngology. JIBI INKOKA TEMBO. 1974; 17(4); 491-493,430.

10. Askar MH, El-Sherif HS, Tomoum MO. Use of a Foley catheter balloon as a tool during endoscopic frontal sinus surgery in a resource-poor environment. Ann Otol Rhinol Laryngol. 2015 Mar;124(3):194-7.

11. Hong SO1, Lee DW, Lee JW, Jung JH. Minimal invasive and cost-effective method in reduction of maxillofacial fracture by using a Foley catheter ballooning technique. J Craniofac Surg. 2013 Nov; 24(6): 585-8.

12. De Freitas RP, Berkowitz RG. Bilateral choanal atresia repair in neonates - a single surgeon experience. Int $\mathrm{J}$ Pediatr Otorhinolaryngol (2012) 76(6).
13. Durmaz A, Tosun F, Yldrm N, Sahan M, Kvrakdal C, Gerek M. Transnasal endoscopic repair of choanal atresia: results of 13 cases and meta-analysis. J Craniofac Surg (2008) 19(5)

14. Riepl R, Scheithauer M, Hoffmann TK, Rotter N. Transnasal endoscopic treatment of bilateral choanal atresia in newborns using balloon dilatation: own results and review of literature. Int $\mathrm{J}$ Pediatr Otorhinolaryngol. 2014;78(3):459-464.

15. Bedwell J, Shah RK, Bauman N, Zalzal GH, Preciado DA. Balloon dilation for management of choanal atresia and stenosis. Int $\mathrm{J}$ Pediatr Otorhinolaryngol. 2011;75(12):1515-1518.

16. Velegrakis S, Mantsopoulos K, Iro H, Zenk J. Longterm outcomes of endonasal surgery for choanal atresia: 28 years experience in an academic medical centre. Eur Arch Otorhinolaryngol (2013) 270(1): $113-6$.

17. Natacha Teissier, MD; Florentia Kaguelidou, MD; Vincent Couloigner, MD, PhD. Arch Otolaryngol, Head Neck Surg. 2008;134(1):57-61.

18. Friedman NR, Mitchell RB, Bailey CM, Albert DM, Leighton SE. Management and outcome of choanal atresia correction. Int $\mathrm{J}$ Pediatr Otorhinolaryngol. 2000;52(1):45-51. 